\title{
Benign Oesophageal Stricture and Chronic Diarrhoea As Atypical Presenting Symptoms of an Advanced Metastatic Pancreatic Gastrinoma: A Case Report and Review of Literature
}

\author{
Muhammad Hafiz Kamarul Bahrin ${ }^{1}$, Raoof Hagag ${ }^{2}$, Abuobeida Ali $^{3}$, Seifeldin Yahia ${ }^{4}$, Richard Armstrong
}

1. Gastroenterology, United Lincolnshire Hospitals Trust, Boston, GBR 2. Acute Medicine, United Lincolnshire Hospitals National Health Service (NHS) Trust, Boston, GBR 3. Gastroenterology, Peterborough City Hospital, Peterborough, GBR 4. Diabetes and Endocrinology, United Lincolnshire Hospitals National Health Service (NHS) Trust, Boston, GBR 5. Gastroenterology, United Lincolnshire Hospitals National Health Service (NHS) Trust, Boston, GBR

Corresponding author: Muhammad Hafiz Kamarul Bahrin, mkamarulbahrin01@gmail.com

\begin{abstract}
Gastrinoma or otherwise known as Zollinger-Ellison syndrome is characterised by hypersecretion of gastrin and gastric acid leading to the formation of recurrent atypical ulcers along the upper gastrointestinal tract. It is extremely difficult to diagnose during an acute presentation both due to its rarity and its lack of pathognomonic symptoms. Its symptoms range from mild to severe to life-threatening and often get mistaken for a different condition such as viral gastroenteritis as seen in our case report. The most common symptoms of gastrinoma include abdominal pain, dyspepsia and chronic diarrhoea. It rarely presents as a benign oesophageal stricture with some case series reporting the frequency to be as low as $0.4 \%$. Our literature review of 9 random case reports on gastrinoma/Zollinger-Ellison syndrome selected from Pubmed Central reviewed the frequency of its presenting symptoms and investigation modalities involved throughout its diagnostic process. In summary, it agrees with the findings postulated by Jensen's series. We also looked into the use of Ga68- DOTATATE-PET/CT as the latest imaging modality used in diagnosing and staging gastrinoma. Once suspected, it is imperative for physicians to investigate it through laboratory, radio-imaging, histology and multidisciplinary led investigating approaches. Depending on its stage, treatment options vary. Early and localised gastrinoma cases are often treated surgically whilst metastasised cases usually resort to treatment with palliative intent.
\end{abstract}

Review began 07/03/2021 Review ended 07/16/2021 Published 07/23/2021

\section{(c) Copyright 2021}

Kamarul Bahrin et al. This is an open access article distributed under the terms of the Creative Commons Attribution License CC-BY 4.0., which permits unrestricted use, distribution, and reproduction in any medium, provided the original author and source are credited.
Categories: Endocrinology/Diabetes/Metabolism, Internal Medicine, Gastroenterology

Keywords: gastrinoma, zollinger-ellison syndrome, benign oesophageal stricture, chronic diarrhoea, pancreatic neuroendocrine tumours

\section{Introduction}

Gastrinoma is a pancreatic neuroendocrine tumour (p-NET). It is extremely challenging to diagnose in an acute setting both due to its rarity and its lack of pathognomonic symptoms. As such, they are usually only diagnosed after years of symptom presentation. Its incidence is between 0.5 and 15 cases per million population and generally accounts for $0.1 \%$ gastric ulcer and $2 \%-5 \%$ recurrent ulcers [1]. Gastrinoma is also referred to as Zollinger-Ellison syndrome (ZES), which is a condition characterised by gastrin hypersecretion, gastro-oesophageal hyperacidity and recurrent atypical ulcers as described by Zollinger and Ellison in 1955 [1]. Gastrinoma is staged according to the standard World Health Organization (WHO) tumour, nodes and metastases (TNM) staging system, which consequently determines its treatment options. Generally, early gastrinoma is treated with curative resection. Liver involvement, with the exception of primary hepatic gastrinoma, indicates poor prognosis and is usually treated conservatively.

There are other forms of p-NET and they are classified generally as functional and non-functional p-NET. The 2012 Consensus Statement by the European Neuroendocrine Tumour Society (ENETS) stated that the two most common functional, malignant p-NETs are gastrinoma and insulinoma. Rarer functional p-NETs account for less than 0.2 cases/million population/year and they include glucagonoma, vasoactive intestinal peptide + oma (VIP-oma), somatostatinoma, GH-oma and ACTH-oma. Very rare functional p-NETs are still under investigation and their incidence remains unknown - they include p-NET secreting PTHrp (PTHrpoma) and p-NET causing serotonin-induced carcinoid syndrome. Non-functional p-NETs often secrete a pancreatic polypeptide, chromogranin A, neuron-specific enolase, human chorionic gonadotrophin subunits, calcitonin, neurotensin or other peptides, but they do not result in clinically significant symptoms manifestation - hence they are largely considered non-functional tumours [2].

We report a case of gastrinoma in an elderly English lady, presenting as recurrent abdominal pain, vomiting and diarrhoea being initially mistaken as a series of acute viral gastroenteritis. Following her admission with worsening symptoms, oesophago-gastro-duodenoscopy (OGD) revealed an extensive oesophago-gastritis, 


\section{Cureus}

benign distal oesophageal stricture and atypical duodenal ulcers, raising suspicion of an underlying gastrinoma. Radio-imaging investigations, histopathology and multi-disciplinary diagnostic meetings confirmed the diagnosis of a pancreatic head gastrinoma with liver metastases. Our patient received conservative management with a good outcome.

\section{Case Presentation}

We report a 79 years old English lady who presented in July 2017 with a complaint of abdominal pain and repeated vomiting for a week. She also reported occasional non-bloody watery diarrhoea over the past one month. She experienced similar symptoms back in January and was diagnosed with acute viral gastroenteritis. Her past medical history includes well-controlled hypertension for which she takes regular amlodipine $5 \mathrm{mg}$ once a day (OD). She does not take any regular medication apart from this. Her family history was unremarkable. On her social history, she denied smoking and drinking alcohol. Physical examination demonstrated stable observation parameters. Clinical biochemistry blood tests showed mild derangement of the liver function test (LFT) with elevated alanine transaminase (ALT) at $64 \mathrm{U} / \mathrm{L}$ (normal range 7-55 U/L) and alkaline phosphatase (ALP) at $329 \mathrm{U} / \mathrm{L}$ (normal range $40-129 \mathrm{U} / \mathrm{L}$ ). She was treated with intravenous (IV) cyclizine $50 \mathrm{mg}$ as a once-off dose and IV $0.9 \%$ sodium chloride at $125 \mathrm{~mL} /$ hour for 24 hours. After three days, her symptoms resolved and she was discharged home with a provisional diagnosis of another acute viral gastroenteritis.

After 13 days following the discharge from the hospital, she re-attended the Emergency Department (ED) with worsening symptoms in addition to a new-onset dysphagia and complete loss of appetite for five days. She also complained of a new-onset watery non-bloody diarrhoea. Physical examination revealed a mildly tender epigastrium without any sign of peritonism. At this point, her haematology and biochemistry blood tests were as shown in Table 1 . She received IV $0.9 \%$ sodium chloride $125 \mathrm{~mL} /$ hour, IV cyclizine $50 \mathrm{mg}$ three times a day (TDS) and IV paracetamol $1 \mathrm{~g}$ four times a day (QDS).

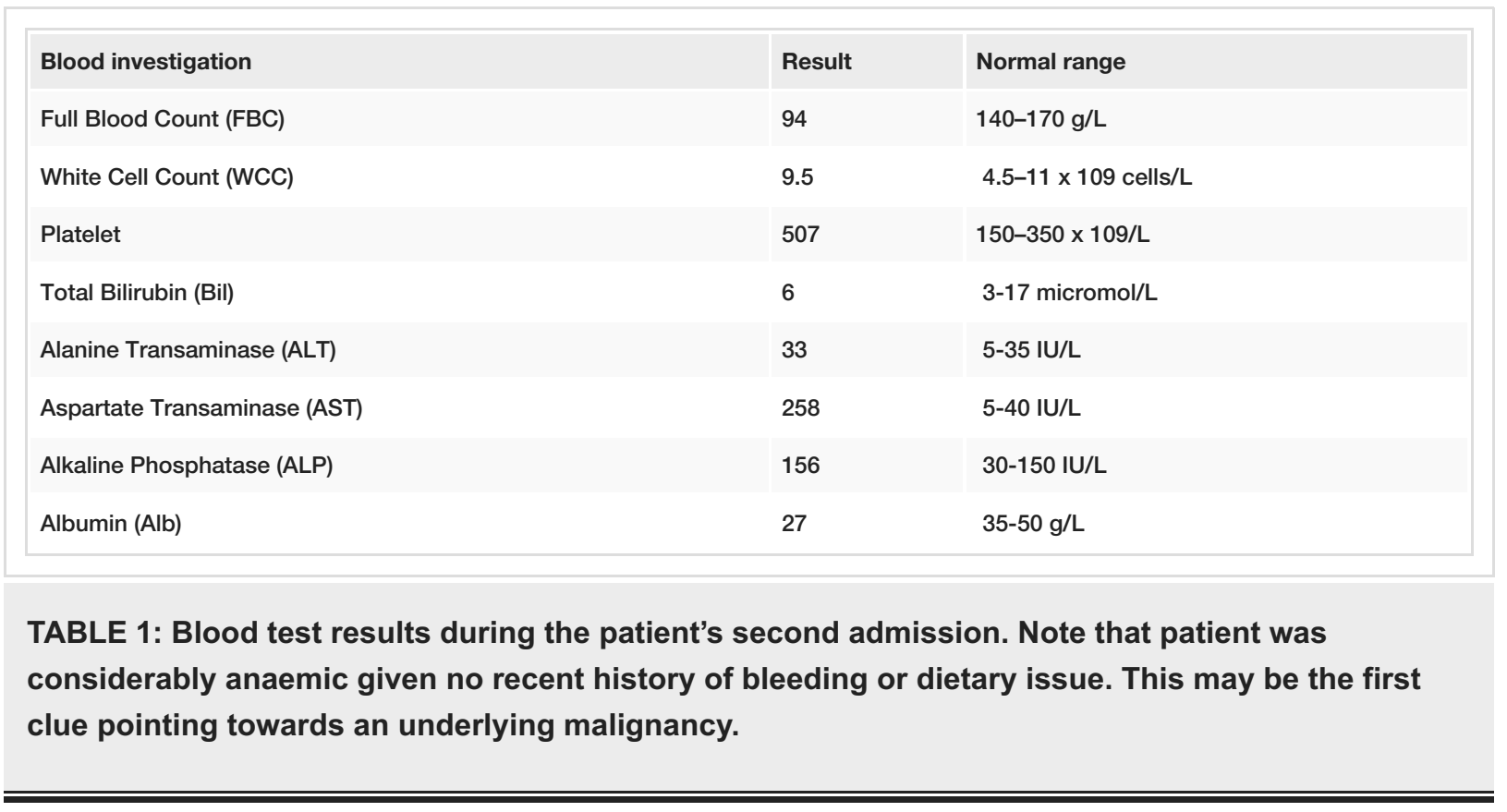

She underwent an OGD the next day, at which point the diarrhoea had stopped. This demonstrated a benignlooking mid-oeosphageal stricture, gastritis, erosive duodenitis in D1 and multiple ulcers with large, ulcerated mucosa in D2. Figure 1 shows the benign stricture image. Unfortunately, no image was taken for the duodenal ulcers in D2. Figure 2 shows the endoscopic dilatation of the benign oesophageal stricture using a wire-guided balloon dilator. Figure 3 shows the post-dilatation appearance of the stricture. Otherwise, no stigmata of upper gastrointestinal bleeding (UGIB) was noted. The abnormal OGD findings led us to a suspicion of a ZES with an underlying malignancy. 


\section{Cureus}



FIGURE 1: OGD image demonstrating a benign mid-oesophageal stricture

OGD - oesophago-gastro-duodenoscopy 


\section{Cureus}

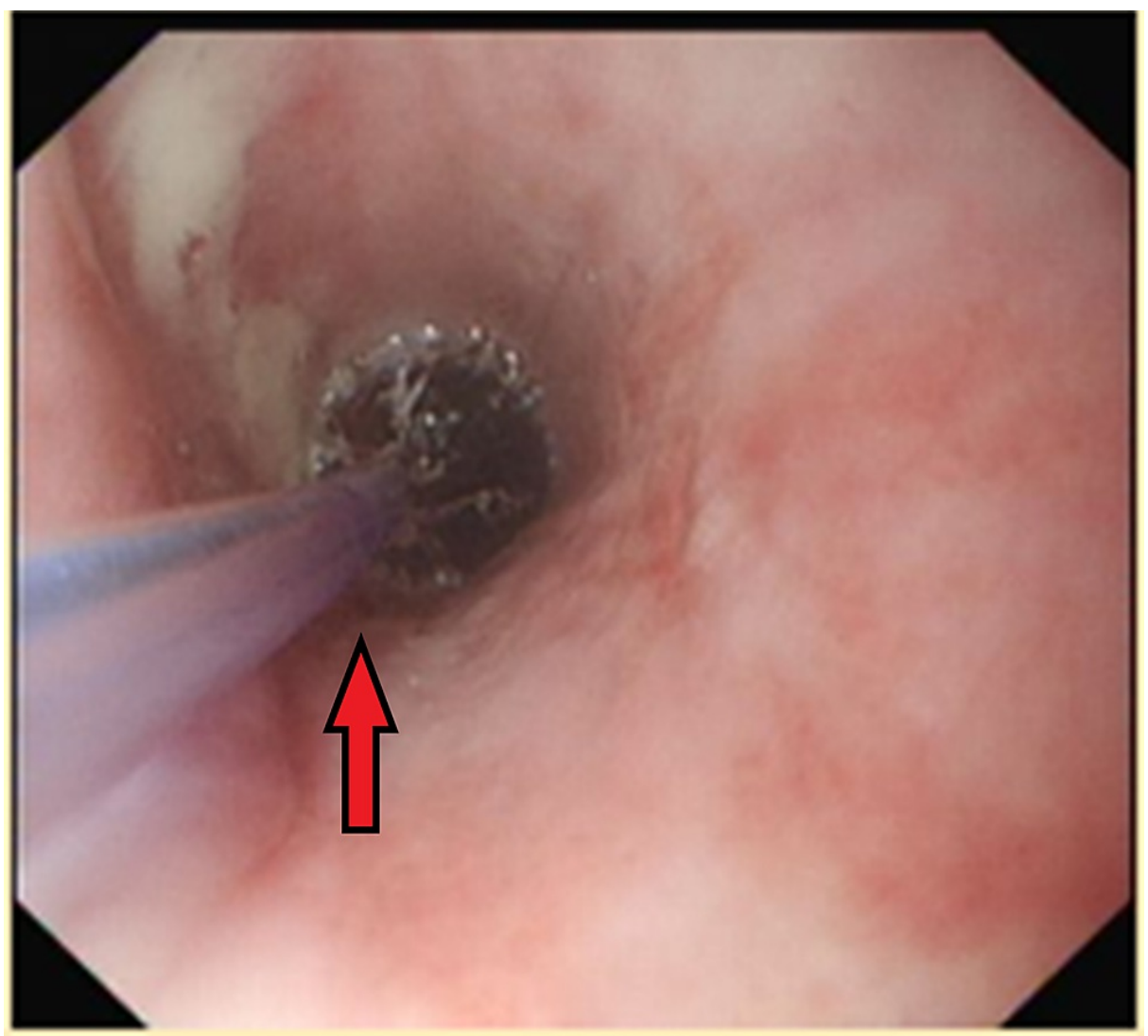

FIGURE 2: Endoscopic dilatation of the benign oesophageal stricture to $12 \mathrm{~mm}$ in diameter using controlled radial expansion (CRE) wire-guided balloon dilatation catheter 


\section{Cureus}

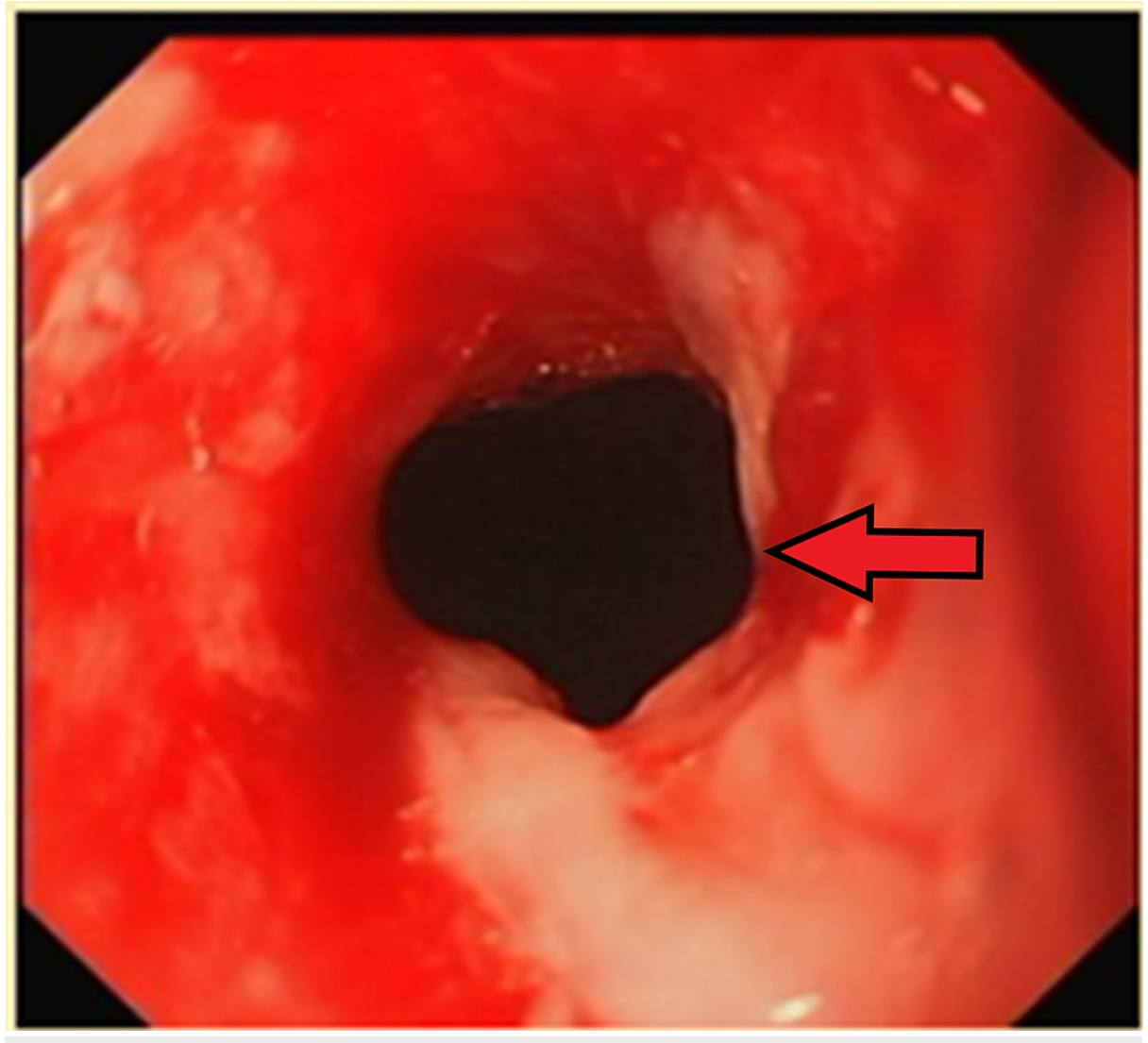

FIGURE 3: Post dilatation appearance of the benign oesophageal stricture

An investigation was followed up with a full-body contrast-enhanced computed tomography (CT) scan. This demonstrated abnormal appearances of the proximal pancreatic head, multiple enlarged para-aortic nodes and hepatic enhancement, raising suspicion of metastases (Figure 4). There was also indeterminate thickening of the gastro-oesophageal junction (GOJ) in keeping with the OGD finding described above (Figure 5). Common bile duct (CBD) was spared from obstruction and our patient remained non-icteric throughout her admission. 


\section{Cureus}

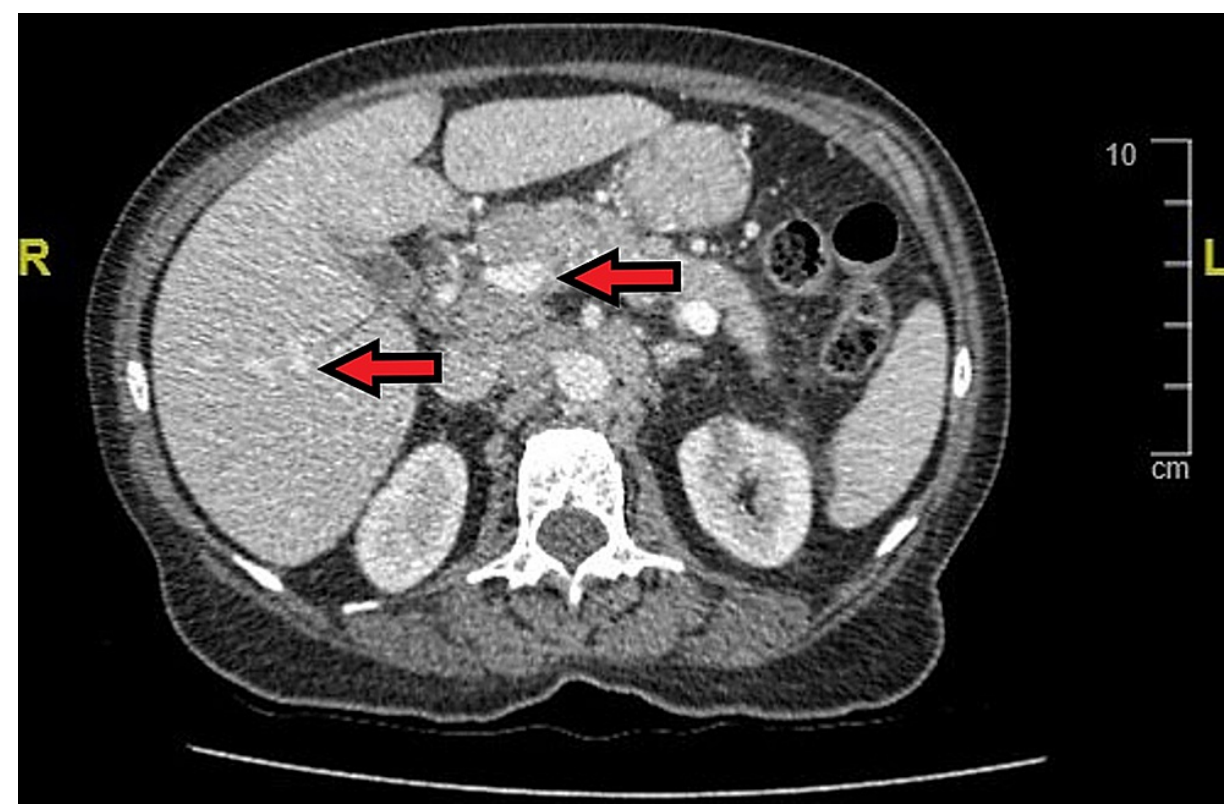

FIGURE 4: Transverse plane view of patient's CT abdomen showing gastrinoma mass (arrows) in the pancreatic head with the appearance of metastatic lesions in the liver

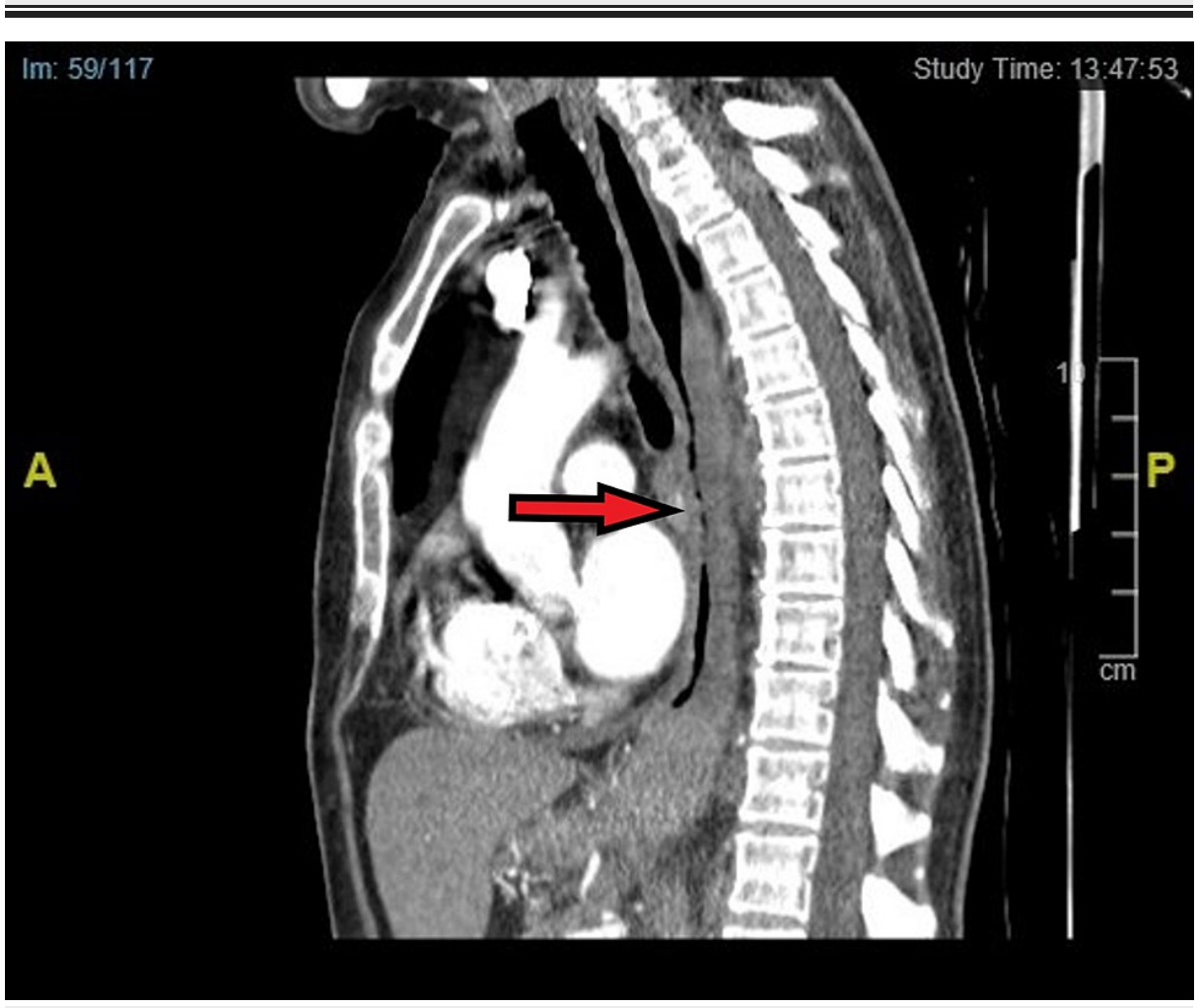

FIGURE 5: Sagittal plane view of our patient's CT thorax showing stricturing oesophagus from middle to distal section

This correlates with our OGD finding as described in Figure 1.

The findings above immediately raised our suspicion of the presence of a neuroendocrine tumour (NET) in the form of gastrinoma. Histology sample was obtained via core needle biopsy of the said liver lesion, which was reported as 'a well differentiated neuroendocrine neoplasm made of monomorphic cells showing positive stain for chromogranin, synaptophysin, CD56 and AE1/AE3 with up to $25 \%$ of tumour cells staining 


\section{Cureus}

for Ki67?. Unfortunately, the histopathology images could not be obtained. She was discharged with a highdose oral proton pump inhibitor (PPI) in the form of omeprazole $60 \mathrm{mg}$ twice a day (BD) and oral cyclizine $50 \mathrm{mg}$ TDS.

Over the next few months, she underwent a further confirmatory tests that consisted of pancreatic neuroendocrine serology tests as shown in Table 2 and a whole-body Ga68-DOTATATE-PET/CT which was reported in Figure 6. Both investigations confirmed the suspected gastrinoma.

\begin{tabular}{|c|c|c|}
\hline Pancreatic neuroendocrine (p-NET) blood test & Result & Normal range \\
\hline Chromogranin A & 409 & 0-60 unit/L \\
\hline Serum Glucagon & $<5$ & $0-50 \mathrm{pmol}$ \\
\hline Serum Pancreatic Polypeptide & $>500$ & 0-300 pmol \\
\hline Serum somatostatin & 29 & 0-150 pmol \\
\hline Serum fasting gastrin & $>400$ & $0-40 \mathrm{pmol}$ \\
\hline Serum Vasoactive Intestinal Pepide (VIP) & 9 & $0-30 \mathrm{pmol}$ \\
\hline
\end{tabular}

TABLE 2: Pancreatic neuroendocrine serology test results for the patient.

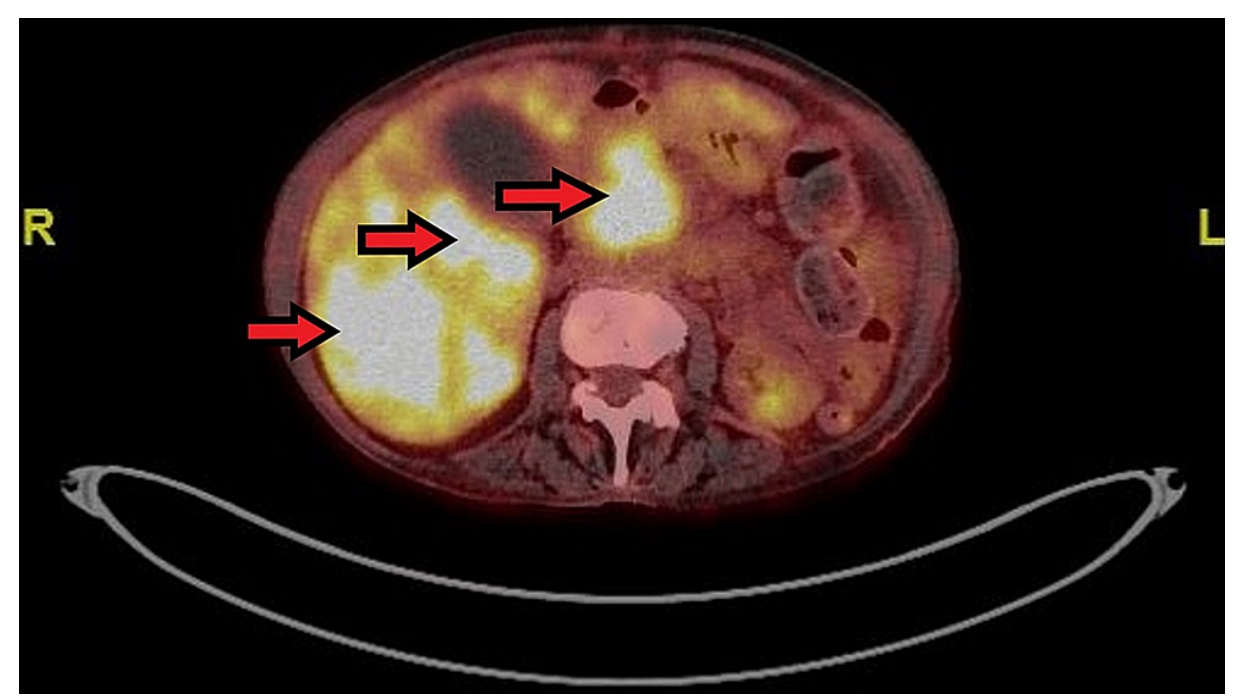

FIGURE 6: Transverse plane view of patient's Ga68-DOTATATE-PET/CT scan demonstrating multiple foci of intense increased tracer uptake within both lobes of the liver and within the proximal pancreas, signifying a metastatic NET

NET - neuroendocrine tumour

Following this, she received a monthly IV somatostatin analogue in the form of Lanreotide $120 \mathrm{mg}$, which was however terminated in early 2019 due to disease progression. She also attended the endoscopy department on a four-monthly basis for palliative endoscopic dilatation of the recurring oesophageal stricture using controlled radial expansion (CRE) wire-guided balloon dilatation catheter to $12 \mathrm{~mm}$ in diameter, intended to alleviate her dysphagia. In view of her advanced age and the metastatic nature of her gastrinoma, she was deemed unsuitable for surgical resection of the tumour - which we were aware of as the gold standard treatment for a NET. The NET multidisciplinary team meeting (MDT) reached an agreement that further management of her gastrinoma should be conservative in nature with palliative intent. She is currently still on an ongoing chemotherapy regime consisting of Carboplatin, fluorouracil and streptozocin. Surveillance CT scan of her gastrinoma in early 2020 demonstrated a relatively stable tumour size and stage. Her quality of life remains unchanged. 


\section{Cureus}

\section{Discussion}

\section{Literature review}

A quick search on Pubmed Central (https://pubmed.ncbi.nlm.nih.gov/) was carried out with regards to gastrinoma and ZES. Nine case reports describing gastrinoma/ZES in nine different patients were selected at random and analysed in terms of their epidemiology, symptomatology, investigation modalities, presence of metastasis and subsequent treatment options. The findings are tabulated as demonstrated in Table 3.

\begin{tabular}{|c|c|c|c|c|c|c|}
\hline Number & $\begin{array}{l}\text { Study, } \\
\text { year }\end{array}$ & $\begin{array}{l}\text { Age, } \\
\text { gender }\end{array}$ & Primary symptoms & Imaging modalities used & $\begin{array}{l}\text { Presence } \\
\text { of } \\
\text { metastases }\end{array}$ & Treatment \\
\hline 1 & $\begin{array}{l}\text { Alshiko et } \\
\text { al., } 2016 \\
\text { [3] }\end{array}$ & $\begin{array}{l}28, \\
\text { female }\end{array}$ & $\begin{array}{l}\text { Heartburn, Diarrhoea, Nausea } \\
\text { and Vomiting, Weight Loss }\end{array}$ & OGD, CT abdomen & None & Surgical resection \\
\hline 2 & $\begin{array}{l}\text { Takami et } \\
\text { al., } 1978 \\
\text { [4] }\end{array}$ & $\begin{array}{l}46, \\
\text { male }\end{array}$ & Heartburn & Immunofluorescence studies & None & Surgical resection \\
\hline 3 & $\begin{array}{l}\text { Aamar et } \\
\text { al., } 2016 \\
{[5]}\end{array}$ & $\begin{array}{l}7, \\
\text { female }\end{array}$ & $\begin{array}{l}\text { Nausea, Vomiting, Diarrhoea, } \\
\text { Haematemesis, Abdominal Pain }\end{array}$ & OGD, CT abdomen, PET scan, & None & $\begin{array}{l}\text { High-dose omeprazole and } \\
\text { octreotide }\end{array}$ \\
\hline 4 & $\begin{array}{l}\text { Baig et al., } \\
2011[6]\end{array}$ & $\begin{array}{l}67, \\
\text { male }\end{array}$ & $\begin{array}{l}\text { Frequent nausea, Vomiting, } \\
\text { Diarrhoea, Haematemesis, } \\
\text { Severe abdominal pain }\end{array}$ & $\begin{array}{l}\text { Octreotide scan, MRI of the } \\
\text { abdomen }\end{array}$ & None & Surgical resection \\
\hline 5 & $\begin{array}{l}\text { Shah et } \\
\text { al., } 2019 \\
{[7]}\end{array}$ & $\begin{array}{l}\text { 60, } \\
\text { female }\end{array}$ & $\begin{array}{l}\text { Nausea, Vomiting, Watery } \\
\text { diarrhoea, Abdominal pain }\end{array}$ & OGD, EUS & None & $\begin{array}{l}\text { Distal Pancreatectomy High-dose } \\
\text { PPI Octreotide }\end{array}$ \\
\hline 6 & $\begin{array}{l}\text { Rivillas- } \\
\text { Reyes et } \\
\text { al., } 2019 \\
{[8]}\end{array}$ & $\begin{array}{l}42, \\
\text { female }\end{array}$ & $\begin{array}{l}\text { Epigastric pain, Melena Signs } \\
\text { of peritoneal irritation }\end{array}$ & OGD & None & Whipple procedure \\
\hline 7 & $\begin{array}{l}\text { Eyal et al., } \\
2014 \text { [9] }\end{array}$ & $\begin{array}{l}53, \\
\text { male }\end{array}$ & $\begin{array}{l}\text { Abdominal pain, Diarrhoea, } \\
\text { Hypomagnesaemia, UGIB }\end{array}$ & $\begin{array}{l}\text { CT scan (Abdomen), OGD, Positron } \\
\text { emission tomography-CT scan } \\
\text { using GA 68-DOTANOC }\end{array}$ & None & Pancreaticoduodenectomy \\
\hline 8 & $\begin{array}{l}\text { Zhang et } \\
\text { al., } 2016 \\
\text { [1] }\end{array}$ & $\begin{array}{l}68, \\
\text { female }\end{array}$ & $\begin{array}{l}\text { Intermittent abdominal pain, } \\
\text { Watery diarrhoea }\end{array}$ & OGD, CT Abdomen, MRI Abdomen & None & Pancreaticoduodenectomy \\
\hline 9 & $\begin{array}{l}\text { Sinagra et } \\
\text { al., } 2013 \\
\text { [10] }\end{array}$ & $\begin{array}{l}61, \\
\text { female }\end{array}$ & $\begin{array}{l}\text { Nausea and vomiting, Watery } \\
\text { diarrhoea }\end{array}$ & OGD & $\begin{array}{l}\text { Liver } \\
\text { metastasis }\end{array}$ & $\begin{array}{l}\text { Total parenteral nutrition (TPN) } \\
\text { feeding, Endoscopic pneumatic } \\
\text { dilation of the esophageal stenosis }\end{array}$ \\
\hline selecte & $\begin{array}{l}\text { 3: A lit } \\
\text { d at ra }\end{array}$ & om & $\begin{array}{l}\text { review of nine case } r \\
\text { rom Pubmed Central. }\end{array}$ & orts on gastrinoma/ & Dlinge & Ellison syndrome \\
\hline
\end{tabular}

The literature review highlights that abdominal pain forms the most common presenting symptom of gastrinoma, followed by heartburn, diarrhoea and vomiting. Four patients developed acute UGIB in response to the underlying gastrinoma. Only one patient reported symptoms of oesophageal stricture, requiring pneumatic balloon dilatation. Expectedly, these findings are in keeping with Jensen's series [11], which highlighted the rarity of oesophageal stricture as a presenting symptom of gastrinoma. Eight out of nine case reports involved the use of OGD at some point during the investigation period - either as the primary investigation leading to suspicion of gastrinoma or secondary investigation to monitor the disease course. Ga68-DOTATATE-PET/CT was only utilised in only 1 case report, with another one utilising the relatively traditional octreotide scan. Surgical resection was pursued in most non-metastatic gastrinoma cases but for the one case involving liver metastasis, the treatment approach was conservative.

\section{Literature analysis}


Gastrinoma is a pancreatic neuroendocrine neoplasm (pNEN) associated with excessive release of gastrin hormone leading to hypersecretion of gastric acid. This subsequently results in hyperacidity of the stomach, recurrent gastro-duodenal ulcers and a minority of cases, severe reflux disease complicating into oesophageal stricture. The vast array of symptoms related to hypersecretion of gastric acid is called Zollinger-Ellison syndrome (ZES). Gastrinoma affects mainly males than females with a prevalence ratio ranging between 1.5:1 and 2:1. It affects people across all age groups, however is predominant between 20 and 60 years old (by up to 90\%) as demonstrated in a study by Hoffman et al. [12].

In most cases (up to $80 \%$ ), gastrinoma presents as sporadic while in the rest $20 \%$ of cases, it presents in combination with other NETs under a condition named Multiple Endocrine Neoplasia Type 1 (MEN-1) [12]. MEN-1 generally involves tumour growths in the parathyroid glands (leading to recurrent hypercalcaemia secondary to excessive parathyroid hormone secretion), pituitary glands (leading to oligomenorrhoea/amenorrhoea/galactorrhoea in females and sexual dysfunction in males secondary to prolactinoma) and the pancreatic neuroendocrine cell. The mode of inheritance for MEN-1 is autosomal dominant in most cases. Sporadic gastrinoma, on the other hand, does not exhibit a specific mode of inheritance hence is more challenging to anticipate [13], especially in an acute setting.

Diagnosing gastrinoma in the UK requires a combination of laboratory testing, radio-imaging investigations and histology. Often management of gastrinoma is made via a coordinated multidisciplinary effort, involving the gastroenterologist, endocrinologist, medical oncologist, surgeon, interventional radiologist and pathologist. Once ZES is suspected, i.e., atypical gastrointestinal ulcers in the absence of Helicobacter Pylori and refractory to acid-suppressive medications, the first step is to check the serum fasting gastrin level in order to rule out gastrinoma. Serum fasting gastrin level of $>200 \mathrm{pg} / \mathrm{mL}$ (NR 100-200 pg/mL) raises the likelihood of gastrinoma. The second step is to rule out other secondary causes of hypergastrinemia such as achlorhydria/hypochlorhydria frequently secondary to PPI or pernicious anaemia. To do this, some centres would carry out gastric $\mathrm{pH}$ measurement via endoscopy or nasogastric (NG) tube gastric suctioning while patients are taken off of PPI for seven days. Gastric $\mathrm{pH}$ of $1,000 \mathrm{pg} / \mathrm{mL}$ is virtually diagnostic for this condition. Similarly, if serum fasting gastrin level increases $>100 \mathrm{pg} / \mathrm{mL}$ but by $200 \mathrm{pg} / \mathrm{mL}$ or twofold above the basal level, this is diagnostic for a primary hypergastrinemia and hence, gastrinoma [14]. Sometimes serum chromogranin A level is also checked; however, this test lacks specificity (67\%) despite having high sensitivity (53\%-91\%) [15].

As with any cancer diagnosis, obtaining a tissue sample is mandatory to determine its grade. This is achieved through core needle biopsy of accessible malignant lesions as visualised on CT or MRI scan. Once obtained, the tissue is stained with Ki67, an immunostaining protein that binds to and picks up proliferating NET cells. Percentage of stained nuclei are then measured and classified into 3 stages. Namely, low-grade NET produces a Ki67 score of $20 \%$ as in this case correlates to high-grade NET [13]. CT and MRI scans would help to determine the extent of the spread of the disease. However, the gold standard imaging modality for the diagnosis of gastrinoma is PET/CT with Octreotide Scintigraphy using Gallium-68 (Ga68) or otherwise known as Ga68-DOTATATE-PET/CT. As indicated in its name, it uses a newer radioisotope of Gallium-68, which can be linked to somatostatin analogues, picked up by the tumour cells and localised by PET/CT scan to give a better picture of the extent of tumour spread. A retrospective single-centre study in the US demonstrated that in contrast to the standard somatostatin receptor scintigraphy, Ga68- DOTATATEPET/CT has a higher sensitivity (90\% vs $65 \%$ ) and overall accuracy ( $88 \%$ vs $68 \%$ ) [16]. Its use is currently extremely limited in the UK, only available in some tertiary referral centres.

Definitive management of a NET such as gastrinoma is achieved through surgical resection of the said tumour for a localised stage. The 20-year survival rate in a primary gastrinoma without metastasis is as high as $95 \%$. Contrastingly, in metastatic gastrinoma cases such as our patients, especially those that had affected the liver, the prognosis is generally poor and surgical resection is usually not feasible and treatment intent is palliative [17]. However, this is debatable as according to a study by Glazer et al., which suggested that early and aggressive surgical management of hepatic metastases from NETs is associated with significant long-term survival rates [18]. Having said so, surgical debulking may be pursued if the tumour growth is large enough to cause a surrounding compression effect.

The first line systemic therapy if the surgical approach is deemed unsuitable, is through symptomatic control by the means of high dose oral PPI (60 mg daily and can be increased up to a maximum of $120 \mathrm{mg}$ daily in two divided doses) and IV somatostatin analogue infusion [19]. Wire-guided oesophageal balloon dilatation is also useful in alleviating the dysphagia symptom according to some case reports. Chemotherapy selection for gastrinoma with metastasis or locally advanced disease consists of 5-Fu, streptozocin and carboplatin. This combination demonstrated an overall favourable outcome in terms of stable disease state post-treatment in $51 \%$ of cases and disease progression in $16 \%$ only, according to a British-based 79 patients prospective study by Turner et al. [20].

\section{Conclusions}

Gastrinoma, being an exceptionally rare type of aggressive malignancy, poses constant diagnostic and management challenges for general physicians. It lacks a pathognomonic set of symptoms to prompt an acute physician to consider its presence at initial presentation, especially during a hectic acute take setting. 
Besides, symptoms associated with the early stage of gastrinoma may also be mild, often masked by widespread prescription of PPI and often being mistaken as acute viral gastroenteritis episodes, as demonstrated in our case report. Authors speculate that the overall impact of the above may potentially lead to delayed diagnosis of gastrinoma, risking narrowing of the available treatment options at the point of diagnosis. The authors also recommend that a worldwide scoring system to risk-stratify patients with potential gastrinoma be established, so that high-risk patients could be investigated at an earlier stage either in the community or in the secondary care setting. Further research or systematic analysis into this subject may be required but not within the remit of this case report.

\section{Additional Information}

\section{Disclosures}

Human subjects: Consent was obtained or waived by all participants in this study. Conflicts of interest: In compliance with the ICMJE uniform disclosure form, all authors declare the following: Payment/services info: All authors have declared that no financial support was received from any organization for the submitted work. Financial relationships: All authors have declared that they have no financial relationships at present or within the previous three years with any organizations that might have an interest in the submitted work. Other relationships: All authors have declared that there are no other relationships or activities that could appear to have influenced the submitted work.

\section{References}

1. Zhang WD, Liu DR, Wang P, Zhao JG, Wang ZF, Chen LI: Clinical treatment of gastrinoma: a case report and review of the literature. Oncol Lett. 2016, 11:3433-7. 10.3892/ol.2016.4397

2. Jensen RT, Cadiot G, Brandi ML, et al.: ENETS Consensus Guidelines for the management of patients with digestive neuroendocrine neoplasms: functional pancreatic endocrine tumor syndromes. Neuroendocrinology. 2012, 95:98-119. 10.1159/000335591

3. Alshikho MJ, Noureldine SI, Talas JM, Nasimian A, Zazou S, Mobaed B, Nasser M: Zollinger-Ellison syndrome associated with von Recklinghausen disease: case report and literature review. Am J Case Rep. 2016, 17:398-405. 10.12659/AJCR.898472

4. Takami H, Yamaguchi K, Abe K, et al.: A case of Zollinger-Ellison syndrome whose pancreatic tumor produced multiple hormones and a review of 48 cases reported in the Japanese literature. Jpn J Clin Oncol. 1978, 8:75-89. 10.1093/oxfordjournals.jjco.a039908

5. Aamar A, Madhani K, Virk H, Butt Z: Zollinger-Ellison syndrome: a rare case of chronic diarrhea . Gastroenterology Res. 2016, 9:103-4. 10.14740/gr734w

6. Baig M, Chin U, Charbel H: Case report: Zollinger-Ellison syndrome. Am J Gastroenterol. 2011, 106:216.

7. Shah I, Vyas N, Kadkhodayan KS: Zollinger Ellison syndrome in a patient with multiple endocrine neoplasia type 1: a classic presentation. Case Rep Gastrointest Med. 2019, 2019:9605769. 10.1155/2019/9605769

8. Rivillas-Reyes JF, Castro-Avendaño JL, Martínez-Muñoz HF: ZollingerEllison syndrome. Case Rep. 2019, 5:28-35. 10.15446/cr.v5n1.71686

9. Eyal A, Sueissa A, Braun E, et al.: From hypomagnesaemia to Zollinger-Ellison syndrome: an adverse effect of a proton pump inhibitor. BMJ Case Rep. 2014, 2014:bcr2014205165. 10.1136/bcr-2014-205165

10. Sinagra E, Perricone G, Linea C, et al.: An unusual presentation of Zollinger-Ellison syndrome. Case Rep Gastroenterol. 2013, 7:1-6. 10.1159/000342355

11. Hoffmann KM, Gibril F, Entsuah LK, Serrano J, Jensen RT: Patients with multiple endocrine neoplasia type 1 with gastrinomas have an increased risk of severe esophageal disease including stricture and the premalignant condition, Barrett's esophagus. J Clin Endocrinol Metab. 2006, 91:204-12. 10.1210/jc.20051349

12. Berna MJ, Hoffmann KM, Serrano J, Gibril F, Jensen RT: Serum gastrin in Zollinger-Ellison syndrome: I. Prospective study of fasting serum gastrin in 309 patients from the National Institutes of Health and comparison with 2229 cases from the literature. Medicine (Baltimore). 2006, 85:295-330. 10.1097/01.md.0000236956.74128.76

13. Cingam SR, Botejue M, Hoilat GJ, et al.: Gastrinoma. StatPearls Publishing, Treasure Island, FL; 2020.

14. Hubbard H: Evaluation of possible gastrinoma. MedGenMed. 2007, 9:31.

15. Goebel SU, Serrano J, Yu F, et al.: Prospective study of the value of serum chromogranin A or serum gastrin levels in the assessment of the presence, extent, or growth of gastrinomas. Cancer. 1999, 85:1470-83. 10.1002/(SICI)1097-0142(19990401)85:7<1470::AID-CNCR7>3.0.CO;2-S

16. Fallahi B, Manafi-Farid R, Eftekhari M, et al.: Diagnostic efficiency of 68Ga-DOTATATE PET/CT as compared to 99mTc-Octreotide SPECT/CT and conventional morphologic modalities in neuroendocrine tumors. Asia Ocean J Nucl Med Biol. 2019, 7:129-40. 10.22038/AOJNMB.2019.39392.1263

17. Fendrich V, Bartsch DK: Surgical therapy of sporadic pancreatic neuroendocrine neoplasias G1/G2 . Visc Med. 2017, 33:344-50. 10.1159/000456630

18. Glazer ES, Tseng JF, Al-Refaie W, et al.: Long-term survival after surgical management of neuroendocrine hepatic metastases. HPB (Oxford). 2010, 12:427-33. 10.1111/j.1477-2574.2010.00198.x

19. Herrera-Martínez AD, Hofland J, Hofland LJ, et al.: Targeted systemic treatment of neuroendocrine tumors: current options and future perspectives. Drugs. 2019, 79:21-42. 10.1007/s40265-018-1033-0

20. Turner NC, Strauss SI, Sarker D, et al.: Chemotherapy with 5-fluorouracil, cisplatin and streptozocin for neuroendocrine tumours. Br J Cancer. 2010, 102:1106-12. 10.1038/sj.bjc.6605618 